\section{Creating a Community of Caring within a School}

\author{
Stacey Keown ${ }^{a}$, Rob Carroll ${ }^{b}$, Jill M. Raisor ${ }^{c, *}$
}

\begin{tabular}{ll}
\hline Received: & 11 December 2019 \\
Revised: $\quad 20$ January 2020 \\
Accepted: $\quad 5$ March 2020 \\
ISSN: 1307-9298 \\
Copyright @ IEJEE \\
www.iejee.com
\end{tabular}

DOI: 10.26822/iejee.2020459469

\title{
Abstract
}

Students often arrive at school not ready to learn due to stress and trauma. In order to thrive in school, students need to know that within the school is an intentional, multi-layered system of caring. This manuscript details strategies at the individual, classroom, and school level. Having targeted strategies to assist students is essential in creating a caring community within the school context.

Keywords: Caring, Stress, Trauma, Community, School

\section{Introduction}

Children who are exposed to trauma are at risk for developing emotional or behavioral problems, including dysregulation, posttraumatic stress disorder (PTSD), depression, low self-esteem, and aggression (Beltran, Brown-Elhillali, Ryce, Ofonedu, Hoover, \& Belcher, 2016). There is research to support that behavior in the classroom can increase teacher workload, stress level, and may be correlated to teacher burnout rates (Friedman-Krauss \& Raver, 2014). A potential strategy to alleviate these issues could be the use of student interventionists in a peer-mediated intervention to build community within the classroom. Student interventionists have served as effective change agents in school settings for both academic problems (Dufrene, Henington, \& Townsend, 2006; Dufrene, Reisener, Olmi, Zoder-Martell, McNutt, \& Horn, 2010) and behavior problems (Arceneaux \& Murdock, 1997).

The following manuscript details strategies for creating a community of caring within the school context. Needs of children entering our classrooms each day are demanding on teachers which can increase the stress level of the classroom. Schools are faced with the unique challenge of meeting the needs of children and supporting teachers while creating an enriching educational atmosphere. Below six strategies total are presented with two strategies highlighted at the individual, classroom, and school levels. The following strategies are practical ideas for establishing a culture of a caring community within the school setting. However, each situation is unique and should be evaluated by appropriate professionals to ensure best practice.

\section{Strategy \#1: Individual Level - Mentoring Program}

A mentorship is a dynamic and reciprocal relationship that can be beneficial for both the child and the mentor (Burrell, Wood, Pikes, \& Holliday, 2001). Community and home-based adult mentors can protect and support a student's resiliency towards overcoming trauma. Children with a mentor, such as a teacher or coach, who support efforts through encouragement and belief, were identified as having higher resilience than those without mentors (Walsh, 2003). Also, when adult mentors demonstrate continued confidence and consistent support in children, the children were far better in adaptive skills than students without an adult mentor (Wong, 2003). According to Blum, McNeely, and Nonnemaker (2002), children were found to benefit from having a stable, trustworthy, non-familial adult on whom they could rely. External mentorship can contribute to growth in all areas of a person's life, in part because mentorship is a combination of multiple processes. These processes include investments of thought, time, and effort that create a capacity for people to expand their capabilities in all capacities of their life (Burrell et al., 2001).

Strategy \#2: Individual Level - Give Hugs, High-fives, or Pats on the Shoulder

Oxytocin is a chemical in our bodies that scientists sometimes call the "cuddle hormone" because levels rise when we hug or sit close to someone else. Oxytocin is associated with happiness and less stress (Cirino, 2018). According to a study conducted by Olff, Langeland, Witteveen, and Denys (2010), oxytocin has been implicated in the pathophysiology of psychiatric disorders. The disorders include abnormal stress regulation as well as disrupted attachment and/or social deficits (e.g., social withdrawal) such as autism, obsessive-compulsive disorder, social phobia, borderline personality disorder, mood disorder, and PTSD. The release of oxytocin reduces amygdala activation and decreases the brain regions involved in automatic and behavioral responses to fear. Young and Wang (2004) link oxytocin with neuroendocrine and psychosocial stress reduction.

Cortisol is public health enemy number one (Bergland, 2013). Ironically, this chemical in our own body, which was designed to activate the fight-or-flight mechanism, could silently harm us. According to Bergland (2013), both eustress and distress release cortisol as part of the general adaptation syndrome. Once the alarm to release cortisol has sounded, your body becomes mobilized and ready for action - but there has to be a physical release of the "fight-or-flight" chemical. If the body fails to release it, cortisol levels build up in the blood, which wreaks havoc on your mind and body. Elevated cortisol levels can interfere with memory and learning, lower immune system functioning and bone density, increase weight gain, blood pressure, cholesterol, and heart disease. Chronic stress and higher cortisol levels also increase one's risk for depression, mental illness, and lower life expectancy.

a Stacey Keown, Department of Teacher Education, University of Southern Indiana, IN, USA. E-mail: srkeown@usi.edu

• Rob Carroll, Department of Teacher Education, University of Southern Indiana, IN, USA. E-mail: recarroll@usi.edu

'Corresponding Author: jill M. Raisor, Department of Teacher Education, University of Southern Indiana, IN, USA. E-mail: jmraisor@usi.edu 
Oxytocin has been observed to reduce the levels of cortisol in the body and lower blood pressure (Dvorsky, 2012). The "tendand-befriend" response increases oxytocin and reduces cortisol (Bergland, 2013). This response is the exact opposite to "fight-or-flight." The "tend-and-befriend" response is linked to increasing healthy social groups to reduce vulnerability, and contributing to the development of social networks (Taylor, Klein, Lewis, Gruenewald, Gurung, \& Updegraff, 2000).

A hug, high-five, or pat on the shoulder can make a person feel safe, secure, and can help reduce their fears. Very rarely is the importance or impact of a hug, high-five, or pat on the shoulder given much thought. A hug, high-five, or pat on the shoulder releases oxytocin which leaves a person feeling tranquil and loved. Oxytocin, along with dopamine and norepinephrine, are believed to be highly critical in human pair-bonding (Dvorsky, 2012).

During a hug, high-five, or pat on the shoulder, oxytocin is distributed throughout the body causing stress reduction and an increase in mood regulations. Through the physical connection, oxytocin can alleviate social anxieties and produce feelings of trust (Dvorsky, 2012; Kosfeld, Heinrichs, Zak, Fischbacher, \& Fehr, 2005). According to Cirino (2018), even touching an inanimate object, such as a teddy bear, can help reduce people's fears about their existence.

Hugs, high-fives, or pats on the shoulder are essential for people with traumatic stress. Oxytocin has been proven to be a natural form of an antidepressant (Dvorsky, 2012). Early stress and abuse experiences (particularly childhood emotional abuse and neglect and early parental separation) seem to disrupt the normal development of oxytocin in children. This development is a critical mechanism to regulate emotional behaviors (Olff et al., 2010). Children with adverse childhood experiences need more oxytocin, which means they could benefit from more hugs, high-fives, or pats on the shoulder It is important to note school policies and children's personal preferences. One idea to consider is to create a chart where the children choose how they prefer to be greeted each day; for example, a high five might help today, but a simple wave might be preferred the next day.

\section{Strategy \#3: Classroom Level - Classroom Champions}

The protégé effect, or using peer-to-peer techniques, can be useful not only in the classroom but in developing a healthier more positive school culture (Price, 2019). When administrators and teachers give students ownership in their learning environments, it creates a sense of pride in students (Price, 2019). An example of how this might work in a classroom is when a student enrolls in school, they will be matched with an identified classroom champion "champ." Students chosen to be classroom champs show leadership skills in knowing school and classroom procedures and have the ability to collaborate well with others. Their role is to welcome new students into the classroom until they have been onboarded successfully into the classroom's culture. The classroom champ's job is to give the new student an initial tour, introduce them to their classmates, teach them their school procedures, and befriend them through this challenging transition. Have the champ greet them each morning upon arrival and walk with them into the classroom. Examples of collaborations might also include things such as playing at recess, eating lunch together, being teammates on a project, etc.

By creating this autonomy within the classroom, character traits, such as-friendship, perseverance, responsibility, respect, self-discipline, cultural sensitivity, and courage-are built (Sheasley, 2019). Belonging in the classroom means ensuring that all students feel welcomed, comfortable, and part of the school family (Dunlea, 2019). Teachers could regularly refer to the character traits in class and consistently link them to learning targets-emphasizing that the traits will help students develop into "their best self". Students and staff share the responsibility for creating a culture of respect and safety, as well as working hard to break down misconceptions that can stand in the way of progress (Sheasley, 2019).

An extension would be to match families together as adult versions of classroom champs, so the families also have a go-to person to ask questions and for reminders or clarity on processes. It is imperative that every child and family feel welcomed in classrooms. Families and schools belong together. They're all strengthened when parents come inside, get acquainted with teachers, and get involved in their kids' learning (Boss, 2010).

\section{Strategy \#4: Classroom Level - Continuity of Care}

Looping, the practice of keeping a group of children with the same teacher for more than a year, has the potential to provide a consistent caregiver during the young child's critical period of attachment and emotional development (Nitecki, 2017). Looping occurs when a teacher is promoted with her students to the next grade level. "Continuous learning," "continuity of care," "continuous progress," or "persisting groups," is the practice of keeping the same caregiver or teacher with a group of children for two to three years (Lab at Brown University, 1997). This classroom practice builds on attachment and continuity of care. The practice of looping stresses long-term relationships, so students of the same age group remain with the same teacher for more than one school year, while multi-age classrooms may have a different teacher year after year (Nitecki, 2017).

Blum, McNeely, and Nonnemaker (2002), found that students benefit from having a stable, trustworthy, non-familial adult they could rely on. Looping provides children with additional time to build the trust and relationships on which much of their learning depends (Haslinger, Kelly, \& O'Lare, 1996). In this setting, children develop stronger social bonds with their peers, are better able to resolve conflicts, and are more skillful in working as team members to solve problems. Looping is especially important for young children, whose social emotional foundation is being built through attachments with parents and caregivers (Nitecki, 2017). . According to Murgatroyd \& Spengler (2011), there is evidence linking early experiences and stressors to physical and emotional problems. The researchers state a solid preventive measure is attachment that a consistent, trustworthy adult could provide. Recent findings based on the implications of epigenetics magnify the need to prioritize the child's need for attachment, especially in settings outside of the home (Nitecki, 2017). The main caregivers are responsible for the "blueprint for baby's own emotional regulations and future expectations of relationships" (KarrMorse \& Wiley, 2012, p. 98). To prevent the negative effects of stress on the child's developing and fragile system, there should be a solid consistent base of attachment (Nitecki, 2017), like those found in looping.

During infancy, toddlerhood, and leading up to age five, there is an "emotional vulnerability of the immature system that is so overlooked in our culture" (Karr-Morse \& Wiley, 2012, p. 97). The widely held opinion about young children is that trauma experienced at a young age is "erased over time, lost in the fog of early experience" (p. 92). This is simply not true. The brains of young children are particularly tuned to both positive and negative emotions in surroundings (Nitecki, 2017). Our schools are where students spend a majority of their day. Within the context of a safe, familiar environment (ex. school settings) with a steady caregiver, attachment can form, which leads to self-regulation, and ultimately maintaining physical, cognitive, and emotional health (Nitecki, 2017). 


\section{Strategy \#5: School Level - Supportive Peers}

Students who experience trauma need to know that they are not alone. Trauma-informed peer support emerged as an alternative to traditional psychiatric hospitalization and has been at the cutting edge of developing new practices for responding to crisis (Felton, 2003). Peer support is grounded in the knowledge that crisis can be transformative, that mutually supportive relationships provide necessary connection, and that new contexts offer new ways of thinking about one's experience. Supportive peers proactively create plans that serve as guidelines to the kinds of interactions and activities that will benefit the student. The situation is shared rather than "handled," and it offers an opportunity for the peer community to learn and grow (MacNeil \& Mead, 2005). Peers can mature together in small groups and learn from each other's challenges based on similar experiences. Oxytocin levels are increased by close relationships and social support, and reduced by sad emotions or social isolation. There is a clear association between oxytocin and the experience of social support (Kosfeld et al., 2005). Peer supports in mental health settings for children who have experienced trauma often mean having peers who have experienced similar hardships working together to address needs (Substance Abuse and Mental Health Services Administration [SAMHSA], 2014). This can be implemented in the school setting as well. In a study conducted by Heinrichs, Baumgartner, Kirschbaum, and Ehlert (2003), students who received both protective factors of social support and oxytocin exhibited the lowest cortisol concentrations during stress exposure, whereas students who received no social support and placebo demonstrated the highest cortisol response. Also, students that have more secure attachments in relationships may be related to having a more positive alliance with therapists, peers, educators, and to their outcomes (Olff et al., 2010).

\section{Strategy \#6: School Wide - Therapeutic Toolbox}

Students who have been traumatized may exhibit a number of challenging behaviors. The multifaceted nature of these challenges often makes such students candidates for individualized behavior support (Cavanaugh, 2016). Certain people or situations may remind the student of their traumatic experience, which could trigger a student's aggressive behavior in the classroom. Once these triggers are identified, support plans can be developed that remove or adjust these antecedents (Crone, Hawken, \& Horner, 2015). It is critical to find time throughout the day for students to demonstrate their strengths and be provided opportunities to engage in activities that interest them (Cavanaugh, 2016). As educators, it is important to celebrate the "small wins". Supporting students with multitiered school-wide supports (MTSS) gives them a safe place to talk about an experience, describe a fear, relieve frustrations, or in some cases, simply provides a friendly face to say hello to everyday. Within some systems of MTSS, the supports include screening, check-in/check-out (CICO), yoga, breathing techniques, and social skills instruction (Bruhn, Lane, \& Hirsch, 2014; Telles, Singh, \& Balkrishna, 2012). By giving students these supports in their therapeutic toolbox, it helps establish a safe environment for them to thrive. In order to be successful, it has been determined that schools must develop, teach, and reinforce at least three to five of these school-wide expectations. (Horner, Sugai, \& Anderson, 2010).

\section{Conclusion}

There are numerous strategies at the various levels (i.e. individual, classroom, and school) that can be implemented to help students cope with a variety of stressors. Educators of students with stress and/or trauma need to be aware of its impact on children, and the most effective ways to address their educational and social needs. Having practical strategies to assist students is essential in creating a community of caring within the school. A simple smile or wave "hello" can provide a strong start to the day. In this manuscript, strategies for building a community of caring within the school are detailed. Each school should consider their unique culture and work collaboratively with students, teachers, staff, administrators, families, and the community to establish a positive, caring atmosphere where optimal learning can occur.

\section{References}

American Psychological Association. (2015). Trauma. Internet site: www.apa.org/topics/trauma.

Arceneaux, M.C., \& Murdock, J.Y. (1997). Peer prompting reduces disruptivevocalizations of a student with developmental disabilities in a general eighth grade classroom. Focus on Autism and Other Developmental Disabilities, 12, 182-186.

Beltran, M., Brown-Elhillali, A., Ryce, P., Ofonedu, M.E., Hoover, D., Belcher, H.E. (2016). Yoga-based psychotherapy groups for boys exposed to trauma in urban settings. Alternative Therapies in Health \& Medicine, 22(1), 39-46.

Bergland, C. (2013). Cortisol: Why the "Stress Hormone" Is Public Enemy No. 1. Psychology Today. Blum, R. W., McNeely, C. \& Nonnemaker, J. (2002). Vulnerability, risk, and protection. Journal of Adolescent Health, 31, 28-39.

Boss, S., (2010). For Kids' Sake, Let's Connect Parents and Schools. Edutopia.

Burrell, B., Wood, S., Pikes, T., \& Holliday, C. (2001). Student Mentors and Protégés Learning Together. TEACHING Exceptional Children, 33(3), 24-29.

Cavanaugh, B., (2016). Trauma-Informed Classrooms and Schools. Beyond Behavior, 25(2).

Cirino, E. (2018). What Are the Benefits of Hugging? Heathline.

Crone, D.A., Hawken, L.S., \& Horner, R.H. (2015). Building positive behavior support systems in schools: Functional Behavioral Assessment (2nd Edition). New York: Guilford Press.

Dufrene, B. A., Henington, C., \& Townsend, A.E. (2006). Peer tutoring for reading fluency: Student implementation and effects on reading fluency. Journal of Evidence Based Practice for Schools, 7, 118-137.

Dufrene, B.A., Reisener, C.D., Olmi, D.J., Zoder-Martell, K., McNutt, M.R., \& Horn, D.R. (2010). Peer tutoring for reading fluency as a feasible and effective alternative in response to intervention systems. Journal of Behavioral Education, 19, 239-256.

Dunlea, M., (2019). Every Student Matters: Cultivating Belonging in the Classroom. Edutopia. Dvorsky, G. (2012). 10 Reasons Why Oxytocin is the Most Amazing Molecule in the World. GIZMODO.

Felton, B.J. (2003). Innovations and implementation in mental health services for homeless adults: A case study. Community Mental Health Journal, 39, 309-322. 
Friedman-Krauss, A.H., \& Raver, C.C. (2014). Child behavior problems, teacher executive functions, and stress in head start classrooms. Early Education and Development, 25, 681-702.

Haslinger, J., Kelly, P., \& O'Lare, L. (1996). Countering absenteeism, anonymity, and apathy. Educational Leadership, $54(1), 47-50$

Horner, R.H., Sugai, G., \& Anderson, C.M. (2010). Examining the evidence based for school-wide positive behavior support. Focus on Exceptional Children, 42, 1-14.

Karr-Morse, R. \& Wiley, M.S. (2012). Scared sick: The role of childhood trauma in adult disease. New York: Basic Books.

Kosfeld, M., Heinrichs, M., Zak, P., Fischbacher, U., \& Fehr, E. (2005). Oxytocin increases trust in humans. Nature, 435(7042), 673-676.

Laboratory at Brown University. (1997). Looping: Supporting Student Learning Through Long-Term Relationships. Brown University Press. Office of Educational Research and Improvement (OERI), Department of Education, under contract no. RJ96006401. Retrieved from http:// www.brown.edu/academics/education- alliance/sites/ brown.edu.academics.educationalliance/files/publications/looping.pdf

MacNeil, C., \& Mead, S. (2005). A Narrative Approach to Developing Standards for Trauma-Informed Peer Support. American Journal of Evaluation, 26(2), 231-244.

Murgatroyd, C., \& Spengler, D. (2011). Epigenetics of Early Child Development. Frontiers in Psychiatry, 2, 16. http:// doi.org/10.3389/fpsyt.2011.00016

Nitecki, E. (2017). Looping and Attachment in Early Childhood Education: How the Applications of Epigenetics Demand a Change. Journal of the Scholarship of Teaching and Learning, 17(2), 85-100.

Olff, M., Langeland, W., Witteveen, A., \& Denys, D. (2010). A Psychobiological Rationale for Oxytocin in the Treatment of Posttraumatic Stress Disorder. CNS Spectr, 15(8), 522-530.

Price, S., (2019). Student-Led Culture Change. Edutopia.

Sheasley, C., (2019). Building a School Like a Tight-Knit Family. Edutopia.

Taylor, S., Klein, L., Lewis, B., Gruenewald, T., Gurung, R., \& Updegraf, J. (2000). Biobehavioral Responses to Stress in Females: Tend-and-Befriend, Not Fight-or-Flight. American Psychological Association, Inc, 107(3), 411-429.

Telles, S., Singh, N., \& Balkrishna, A. (2012). Managing Mental Health Disorders Resulting from Trauma through Yoga. Depression Research and Treatment, 2012 doi:10.1155/2012/401513

Substance Abuse and Mental Health Services Administration (SAMHSA). (2014). Trauma- informed care in behavioral health services. Treatment Improvement Protocol Series 57. ockville, MD: Substance Abuse and Mental Health Services Administration. http://www.samhsa. gov/nctic/ trauma-interventions

Walsh, F. (2003). Family resilience: a framework for clinica practice. Family Process, 42, 1-18
Wong, B. Y. L., (2003). General and specific issues for researchers' consideration in applying the risk and resilience framework to the social domain of learning disabilities. Learning Disabilities Research \& Practice, 18, 68-76.

Young, L. J., \& Wang, Z. (2004). The neurobiology of pair bonding. Nat Neurosci, 7(10), 1048-1054. 